\title{
"Does Paranormal Perception Occur in Near-Death Experiences?" Defended
}

\author{
Keith Augustine, M.A. \\ Internet Infidels, Colorado Springs, CO
}

\begin{abstract}
Four preceding commentaries present a variety of criticisms of "Does Paranormal Perception Occur in Near-Death Experiences?": that most near-death researchers do not interpret near-death experiences (NDEs) as evidence for life after death; that near-death researchers never appeal to NDE accounts incorporating predictable or uncorroborated details as evidence for veridical paranormal perception during NDEs; that reliable data contradict my critique of near-death veridicality studies; that it is unscientific to suggest a role for embellishment in NDE reports; that the patient in the Maria's shoe case reported veridical details that she could not have learned about through conventional means; and that my critique of the Pam Reynolds case amounts to an " $a$ priori dismissal" of features suggesting veridical paranormal perception or consciousness in the absence of brain activity. I respond to each of these and other criticisms in kind.
\end{abstract}

KEY WORDS: out-of-body experiences; survival hypothesis; veridical paranormal perception; embellishment; anesthesia awareness.

According to Bruce Greyson, my critique of near-death veridicality research - particularly my claim that the majority of near-death researchers interpret NDEs as evidence for survival after death - is founded on "unsubstantiated speculation from the popular media" rather than any scientific data or scholarly literature. In fact, the claim is an inference based on the explicit comments of prominent near-death researchers themselves, including the very researchers

Keith Augustine, M.A., is Executive Director and Scholarly Paper Editor of Internet Infidels, a nonprofit educational organization dedicated to defending and promoting metaphysical naturalism on the Internet. Reprint requests should be addressed to Mr. Augustine at Internet Infidels, PO Box 142, Colorado Springs, CO 80901-0142; e-mail: kaugust@infidels.org. 
Greyson cites, as well as the focus of their research. Admittedly, the inference is not supported by any direct survey data; to my knowledge no surveys on the beliefs of near-death researchers have yet been done. But it is specious to describe my claim as the result of nothing more than how near-death researchers have been portrayed by the popular media. Moreover, there are some relevant, albeit indirect, survey data here.

First, in 1980 Robert McConnell and T. K. Clark published a survey of the beliefs of 203 members (84 percent) of the Parapsychological Association. McConnell and Clark found that the parapsychologists surveyed were most skeptical about the case for survival after death, with only 11 percent of Parapsychological Association members affirming that survival had either been demonstrated by, or made probable in light of, the parapsychological evidence. Moreover, prominent parapsychologists have been ambivalent about the relevance or import of existing parapsychological evidence to the survival question (Broad, 1925; Broughton, 1991; Irwin, 2002; Radin, 1997).

By contrast, near-death researchers are far more likely to be sympathetic to life after death. Greyson notes that "The vast majority of near-death researchers are nurses, physicians, and other clinicians." A 2005 survey by Farr Curlin, John Lantos, Chad Roach, and Sarah Sellergen found that American physicians were roughly one-and-a-half times more likely to affirm life after death than scientists in general, with 59 percent of American physicians reporting belief in life after death, as compared to the 38 percent of American scientists who expressed belief in "human immortality" in a 1996 survey by Edward Larson and Larry Witham. By comparison, the 1998 General Social Survey found that about 82 percent of the general population of the United States affirmed belief in life after death (Greeley and Hout, 1999). Thus rates of belief in life after death among nurses and other clinicians are almost certainly even higher than those among physicians.

Greyson accuses me of conflating "scholarly near-death research with popular or New Age writings" on NDEs. But this is simply not the case. I said that the majority of near-death researchers believe that NDEs provide evidence for life after death, regardless of what they think near-death research has scientifically established. Surely there is a distinction between how a researcher assesses evidence as a scientist - what he or she believes the field has demonstrated and what he or she personally believes to be the best interpretation of that evidence as an individual. 
Near-death researchers as a whole may "show little if any interest in the question of survival of death," but that would be no indication that they lack such interest. Hence Greyson's claim that "Only a small minority of near-death researchers even address the possibility of postmortem survival" in academic publications is entirely compatible with my claim that the majority of them interpret NDEs as evidence for survival. Researchers are far more guarded about their conclusions within the scholarly literature than in what they personally believe; and except for the most stoic of scholars, personal beliefs are typically revealed in interviews and popular works. Moreover, if "few of those [who publish academic work on NDEs and survival] could be said to regard NDEs as proof of survival of bodily death," surely that is because they know the difference between personal interpretations of the findings of near-death research, and what findings near-death research has established.

Accordingly, that most NDE research "has focused on transformations in attitudes and values that are reported by NDErs" is hardly surprising, whatever the beliefs of near-death researchers. It is much easier to answer straightforward empirical questions about the transformative effects of NDEs than it is to establish their ontological significance. And as far as beliefs about survival are concerned, the real issue is not whether "speculations about physiological mechanisms possibly underlying the phenomenon" constitute a considerable portion of the near-death literature, but whether near-death researchers as a whole tend to promote or discredit purely physiological explanations of NDEs.

Most near-death researchers tend to (hastily) conclude that if current models cannot fully explain NDEs, that is because no purely psychophysiological explanation of them is possible. Penny Sartori's speculations are typical:

Previous arguments against [transcendental interpretations of] the NDE are no longer valid. Such discoveries indicate that the current scientific worldview needs to be revised and expanded. According to the current worldview, consciousness is merely a by-product of the brain and without the brain there can be no conscious awareness. However, [NDE] research ... appears to demonstrate that conscious awareness does occur when the brain has ceased to function. (2004, p. 39 ; italics added)

Indeed, prominent near-death researchers are apt to employ a mutually reinforcing dual strategy to undermine any psychophysiological explanation of NDEs: appealing to veridical perceptions that 
purportedly cannot be explained by normal means, and claiming that NDEs occur during a period of no brain activity. Consider the concluding comments of Pim van Lommel and colleagues:

How could a clear consciousness outside one's body be experienced at the moment that the brain no longer functions during a period of clinical death with flat EEG? ... Furthermore, blind people have described veridical perception during out-of-body experiences at the time of this experience. (van Lommel, van Wees, Meyers, and Elfferich, 2001, p. 2044)

That consciousness ever functions outside of the body during NDEs is the very issue in dispute. The Reynolds case is widely celebrated precisely because researchers have erroneously attributed both features - veridical paranormal perception and consciousness without brain activity - to Reynolds's NDE. While technically these features "do not necessarily tell us anything about postmortem conditions," if ever jointly demonstrated (with veridicality allowing us to correlate perceptions to a period of brain inactivity), they would show that consciousness can persist independently of a functioning brain, and that would make it quite "conceivable that [minds] are capable of functioning after the body dies" (Greyson 2000, p. 341). I doubt that any near-death researcher who believes that the mind can function in the complete absence of brain activity for any period of time nevertheless believes that it ceases to exist once brain activity permanently ceases. Such minimalistic dualism is probably as close as one can get to affirming survival without actually doing so.

Consequently, advocating consciousness in the absence of brain activity is tantamount to advocating discarnate survival. While awareness in the absence of brain activity does not technically demonstrate the postmortem persistence of consciousness, the issue is what most near-death researchers believe, not what they can prove. And few near-death researchers, I suspect, would deny that an actual separation of mind and body implies survival after death (making it more likely than not), even if it does not strictly entail it.

In any case, Greyson acknowledges that near-death researchers may very well tend to emphasize NDE cases with "the more problematic features that suggest a disconnect between mind and body," while neglecting cases with hallucinatory features that tend to undermine such a disconnect, or at least the need to postulate one. And this is the fundamental issue here. For if the majority of neardeath researchers approach the phenomenon assuming that NDEs 
provide evidence for mental activity outside of the brain, that will surely color how they do their NDE research.

Such a bias has already impacted what sorts of issues near-death research has addressed. Countless examples could be enumerated. First, there are attempts to rule out all purely physiological explanations of NDEs. Second, there are experiential comparisons between NDEs and drug-induced or naturally occurring hallucinations, clearly motivated by a desire to distinguish NDEs from these other things. Similar comparisons have been made between spontaneous OBEs and electrochemically induced ones (for example, ketamine-induced OBEs or OBEs resulting from electrical stimulation of the temporo-parietal junction). Third, near-death researchers have repeatedly argued, despite few reliable data, that NDEs are remarkably consistent across cultures, no doubt to bolster the notion that purported crosscultural consistency results from a shared external reality. Finally, there is a concerted effort to corroborate the paranormal nature of NDEs, whether in the systematic search for "veridical cases," compilations of NDErs' claims to have gained psychic abilities after their NDEs or prophesied future events during them, or reports of NDErs seeing recently deceased persons they could not have known about beforehand during their experiences.

Perhaps Greyson should survey previous issues of the Journal of Near-Death Studies for those sorts of issues instead of sparse explicit discussions of survival. A substantial portion of the near-death literature addresses them. Little near-death research, by comparison, has been devoted to divergent ends. Just how much near-death literature has aimed to bolster psychophysiological explanations of NDEs, note similarities between NDEs and other kinds of hallucinations, emphasize variability in NDE content between cultures, or question the quality of the data claiming NDEs with paranormal characteristics? Some of the literature has aimed to do these things; but overall, it is undeniably unbalanced. For instance, there is nothing even remotely like a concerted effort by any prominent near-death researcher to document known hallucinatory NDE cases.

Greyson's citation of Raymond Moody and Kenneth Ring, of all investigators, as examples of prominent near-death researchers who do not take NDEs to be evidence for survival is surprising. According to Greyson, Moody even insists "that NDEs cannot provide evidence for survival" when he writes: "I have never equated ... my reporting of so-called 'near-death experiences' with a declaration on my part of the 
unquestioned existence of 'life after death." But Greyson's inference does not follow from Moody's words: Moody has simply acknowledged that NDEs do not constitute proof of survival, not that they provide little or no evidence for it. And it strains credulity to think that Moody does not personally believe in life after death after authoring or coauthoring titles like Life After Life: The Investigation of a Phenomenon - Survival of Bodily Death (Moody, 1975), Reunions: Visionary Encounters with Departed Loved Ones (Moody and Perry, 1993), and Life Before Life: Regression into Past Lives (Moody and Perry, 1990).

Of course, researchers like Moody might speculate on the "discoveries" of survival research, endorse hypnotic past-life regression, and facilitate visions of deceased relatives through ancient Greek divination techniques solely for therapeutic purposes, without believing in life after death; but it does not seem particularly likely. Is it not exceptional for past-life investigators to doubt the reality of reincarnation, or alien abduction hypnotherapists to reject the reality of extraterrestrial visitation? Fortunately, we can move beyond extrapolation and confirm that Moody both believes in life after death and takes NDEs to be evidence for it:

I find that even after I have asserted that I am not trying to prove that there is life after death and have made all of my usual qualifying remarks, some people ... . want to know what I, Raymond Moody, feel... I I have come to accept as a matter of religious faith that there is a life after death, and I believe that the phenomenon we have been examining is a manifestation of that life. $(1977$, p. 111)

And while Ring may have once asserted that NDEs "do not and cannot [even] suggest the existence of an afterlife," it is doubtful that a researcher with a curriculum vitae dedicated to corroborating "prophetic visions" and "veridical perception" during NDEs could really believe that. After all, Ring described the Maria's shoe case as "the single best instance we now have in the literature on NDEs to confound the skeptics" (2000, p. 218). And what, pray tell, does it confound the skeptics about? Certainly not whether NDEs occur, but rather how to interpret them. If there is any remaining doubt, one need only consult Ring's Lessons from the Light, where after describing preoccupation with an afterlife as "a distraction ... that can draw us away from the lessons we have come into a body to learn and practice here" (Ring and Valarino, 2000, p. 281; italics added), he nevertheless confirms that he believes in life after death and thinks that NDEs tell us something about it: 
There are many books ... filled with accounts of afterdeath communications or deathbed visions, or apparent reincarnational episodes or regressions into possible states of consciousness between lives whose findings are highly congruent with the implications of NDEs and with the hypothesis of survival following bodily death. And had I chosen to, I could have cited many such cases ... that would have added even more evidence in support of an afterlife... .

[W] hat the NDE really teaches about the afterdeath is that we are at this very moment and throughout our lives writing the script that will govern our soul's posthumous journey - that no one other than we ourselves is [sic] the shaper of our soul's destiny after death... . Not just what we are in our essence, but how we have in fact lived will be evident - perhaps painfully so - after death. (Ring and Valarino, 2000 , pp. 281 and 283; italics added)

After citing my reference to Tillman Rodabaugh's example of a physician wearing green scrubs during surgery, Greyson protests that near-death researchers never appeal to NDErs' "high probability guesses" as evidence of veridical paranormal perception during NDEs, but rather cite "only descriptions of extremely low antecedent probability." But, in fact, prominent near-death researchers have cited likely details as evidence of veridical paranormal perception during NDEs, as well as details that it would be difficult to guess correctly but which have not been corroborated.

I have already illustrated the latter in Mark Fox's critique of studies of NDEs in the blind. The former is illustrated by Michael Sabom's comments on the visual details of Reynolds's OBE: "I was shocked with the accuracy of Pam's description of the saw as an 'electric toothbrush' with 'interchangeable blades"' (1998, p. 187). (I defer the reader to Gerald Woerlee's sketch of why this particular detail constitutes a likely detail, already cited in "Does Paranormal Perception Occur in Near-Death Experiences?") Appeals to likely details as evidence of veridicality can also be found in Kenneth Ring's Lessons from the Light, where the first half of the second chapter is devoted to a half dozen cases of NDErs reporting observations of dust on top of hospital light fixtures during OBEs (Ring and Valarino, 2000), hardly the sort of detail that would astonish anyone who has done a little housecleaning. One particular example is noteworthy for combining likely details with purportedly accurate but uncorroborated details that it would be difficult to correctly guess:

In finite detail, I saw the dust on the supposedly clean and sterile $O R$ lights [predictably, an area that janitors could easily overlook], someone just outside smoking a cigarette [discernable by smell], the 
near-panic of the medical staff [predictable and discernable by hearing], and the expression of the big, black Air Force corpsman who was called to come in to forklift me in his arms to get me on my back. He had a clearly discernable scar on the top of his closely cropped head, in the form of a small cross [not predictable or easily discerned at the time, but uncorroborated and discernable after-thefact]. He was the only one not wearing a face mask, having been summoned on the spur of the moment [uncorroborated and discernable after-the-fact]. He watched as the staff tried to pound life into me, pounding on my chest, pushing, seemingly forever [predictable and discernable by touch or hearingl. (Ring and Valarino, 2000, p. 61)

The anecdotal nature of these reports virtually ensures that they will never amount to compelling evidence for veridical paranormal perception during NDEs, as it is nearly impossible to rule out lucky high probability guesses, specific prior knowledge of the procedures generally involved (perhaps suppressed by cryptomnesia), or the acquisition of unique accurate information by normal means during or subsequent to such experiences. This is why controlled studies utilizing hidden visual targets are critical for the future of NDE veridicality research.

Greyson cites Sabom's study of NDErs' descriptions of cardiopulmonary resuscitation (CPR), which found that nonNDErs were far more likely to imagine inaccurately or describe only vaguely CPR procedures compared to NDErs who claimed to have witnessed their own resuscitations during OBEs. But Sabom did not use the proper control group; he compared NDErs who underwent CPR with nonNDErs who were not resuscitated. As Susan Blackmore has already noted:

[T] he real NDErs actually went through the procedure. If they had had any residual sensory ability they might have heard things and felt things that were going on and this would allow them, in their vivid imaginations, to piece together the procedure much more accurately. Sabom's control group ... did not have access to anything like as much information as the real patients. $(1993$, p. 120)

Michael Potts added that corroboration for the specific details unique to the NDErs' own resuscitation was lacking in Sabom's study:

Without the details of the resuscitation in the medical records, which often leave out the specific details of procedures used, there is no accurate way to check a patient's account to determine whether it is accurate. Also, some NDErs were interviewed years after their resuscitation, and that is more than enough time for these patients to learn about the specifics of CPR, especially since they were 
resuscitated and might be interested in learning about the procedures used. (2002, p. 250)

The continuation of Potts' discussion succinctly captured the actual state of the evidence for veridical paranormal perception during NDEs:

Blackmore went on to note that in cases of "distant vision" ... the reports of the NDEr are usually not specific enough to warrant belief in [accurate] visual experience, such as a boy who noticed that his two dead grandfathers had brown and black hair. But as Blackmore pointed out, brown and black are very broad descriptions of a wide range of hair colors... .

... If there were cases of NDEs in which patients recalled visual information that could only been learned by actually being outside the body, such as recalling specific details of the clothing worn by the code team, specific details of the resuscitation including the order of events, or details of the room in which the resuscitation occurred that could have only been learned by actually being there, then this would support the out-of-body interpretation of NDEs, which could then be used as evidence of a "minimalist life after death." If reports of NDErs seeing those whom they did not know were dead turn out to fit the facts of the case, then this would seem to mark some evidence of continuation of life beyond biological death. It is thus possible that NDEs could be used to make a strong case for a "minimalist" life after death; but such evidence is lacking at present. (2002, pp. 250-251)

If there were evidence of the sort Potts outlined, then the data would contradict my critique of near-death veridicality studies; but, as Potts also noted, anything of the sort has yet to happen.

Next Greyson touches upon the true heart of the matter in the ongoing dispute between skeptics and believers over the best way to interpret NDEs. He charges me with being unscientific in assuming that NDE reports claiming veridical paranormal perception "were embellished or otherwise distorted." However, in offering such alternative explanations, it was not my intent to definitively establish that such reports were embellished or contaminated, but simply to show that they could have been. And as Greyson correctly points out, just because "investigators could have asked experiencers leading questions or ... corroborating witnesses could have lied or ... NDErs could have remembered incorrectly," it does not follow that any of them did do those things.

Nevertheless, the issue is not whether one can demonstrate these alternative explanations, but where the probabilities lie. Given the extraordinary nature of claims of veridical paranormal perception, the 
burden of proof falls on proponents to rule out more mundane, and antecedently much more likely, sources of supposedly paranormal information. This is an epistemological requirement that even seasoned parapsychologists recognize, as when Stephen Braude attempted to rule out normal sources of potential survival evidence he dubbed "the Usual Suspects," such as fraud, misreporting, malobservation, and cryptomnesia, before making a positive case for survival $(2003$, p. 10$)$. This burden falls on proponents because embellishment, memory distortion, and interviewer feedback are established features of human psychology whose reality is not in dispute, whereas the reality of genuinely paranormal phenomena is highly contentious.

Parapsychologists have failed to convince the larger scientific community of the existence of any paranormal phenomena. Indeed, parapsychologists cannot even agree amongst themselves about which purportedly paranormal phenomena are genuine, as McConnell and Clark's survey demonstrated. Furthermore, there is little evidence of progress within parapsychology: A century and a half of parapsychological research has failed to yield so much as a single indisputable parapsychological fact, let alone anything that could be called a body of knowledge for future generations of parapsychologists to build upon. And while Greyson correctly notes that several years of direct research within controversial disciplines like parapsychology does not represent the substantial investment one might find in, say, genetic research, that does not entail that substantial resources have not been incidentally enlisted to test the paranormal. Nicholas Humphrey pointed out that

tests of the limits of people's normal powers of perception have been run again and again in conventional psychological laboratories, using methods that would be exquisitely sensitive to any kind of information transfer... . And in literally thousands of experiments they have established that there really are sensory stimuli that people cannot see ... even when these stimuli are physically distinct and known to another person. In these thousands of experiments they have therefore incidentally, but nonetheless conclusively, shown that ESP does not occur. (1996, p. 139)

Peter Geach reiterated the point concerning ostensible evidence for survival. Considering that today there are 10 to 20 times as many deceased human beings as living ones (Dillard, 2000; Haub, 1995; Thatcher, 1996), if something leaves the body during OBEs or after death and can interact with the physical world, as out-of-body vision would require, why is it the case that 
"subtle bodies" have never forced themselves upon the attention of physicists, as X-rays did, by spontaneous interference with physical apparatus? There are supposed to be a lot of "subtle bodies" around, and physicists have a lot of delicate apparatus; yet physicists not engaged in psychical research are never bothered by the interference of "subtle bodies." (Geach, 1992, p. 226)

Given our well-established background knowledge of what is known to be real, normal factors like deception and errors in observation, memory, or reporting are always going to be antecedently much more likely sources of claims of veridical paranormal perception than actual paranormal factors, at least until such time that the reality of the paranormal is no longer in dispute. Consequently, extraordinary claims like those of veridical paranormal perception require much greater evidential justification than ordinary claims like embellishment. That people are known to embellish is an indisputable fact, but that people have ever been known to perceive outside of the body is arguable at best. Hence normal explanations for NDE accounts must be ruled out decisively before appeals to paranormal explanations are warranted.

Greyson points out that, despite his preliminary findings suggesting that the longer the delay between having an NDE and reporting it, the more intense the NDE reported, a more conclusive follow-up study found no such effect suggesting embellishment in NDE reports over time. I applaud Greyson for following up on his preliminary finding. However, I never claimed that that finding was anything more than suggestive, and cautioned the reader that it "may have been peculiar to that particular sample of NDErs" rather than something that should be generalized to all NDErs, particularly in light of the conflicting findings of two similar studies. Indeed, I never claimed that either his preliminary finding or the results of any follow-up study would definitively confirm or falsify the role of embellishment in NDE reports. Instead, I merely noted that a follow-up study would "definitively determine the extent of embellishment in NDEs."

What Greyson's most recent study has established is that, between the first and second reports of their experiences, his NDErs as a whole were not particularly prone to embellish. However, it remains to be seen whether NDErs who, in particular, report more elaborate or coherent NDE narratives, or NDEs with paranormal elements, are prone to embellishment, such as those claiming veridical paranormal perceptions during out-of-body NDEs, accurate prophetic visions shown to them during their experiences, or encounters with recently 
deceased persons they did not know about at the time of their NDEs. Moreover, since an average of 17.7 years passed between the NDE itself and the first report of it, if any embellishment had occurred in the nearly two-decade interval between the NDE and its first report, it would not have been detected in Greyson's follow-up study, as Greyson himself acknowledged (Greyson, 2007).

Since reports of elaborate or ostensibly paranormal NDEs constitute only a small subset of NDE accounts, Greyson's follow-up study does not shed much light on the extent to which, say, NDErs reporting rich narrative plots, or claiming veridical paranormal perceptions during OBEs, tend to embellish. That is why I characterized Greyson's preliminary finding as merely suggestive, and why I mentioned that another study by Carlos Alvarado had found that although about 20 percent of his OBErs claimed "verifiable observations" during their experiences, only about 5 percent of them even "qualified as potentially veridical when experients were asked to provide fuller descriptions" (Alvarado, 2000, p. 187). Alvarado's study provides more direct evidence that OBErs claiming paranormal veridicality tend to embellish, although that tendency might also be peculiar to Alvarado's sample and not something that can be generalized to all OBErs or even to out-of-body NDErs.

On target identification experiments, I concur that a mere dozen out-of-body NDEs to test hardly settles the issue of veridical paranormal perception during NDEs. That is why I concluded merely that "existing veridicality research presents no challenge to the current scientific understanding of near-death experiences as hallucinations," and why I urged the continuation of such experiments. I share Sartori's desire to engender "hundreds" of out-of-body NDEs in a controlled setting so that we can answer this question confidently one way or the other.

Regarding the Maria's shoe case, I never denied that Maria was a real person. Indeed, that Maria has long been deceased is hardly the sort of presumption one would make about a fictional character. So I do not know who Kimberly Clark Sharp is addressing when she writes that "there was a Maria who observed and reported everything Keith Augustine wrote." It is also unclear why she brings up nondescript "others" who deny that the shoe ever existed, since neither I nor my source ever denied the existence of the shoe. Indeed, the investigators whose analysis I summarized performed tests with their own tennis shoe to determine what one could discern about such a shoe from 
various locations, and the very performance of those tests implicitly grants the existence of a shoe behind the "legend."

Sharp writes that she had never addressed skeptical critiques of the case because they have never been worth her time. But that strikes me as an odd reaction to a critique as abundantly "full of holes" as she claims. A critique so wrought with errors should make a researcher more inclined to point out at least a few of the most prominent ones. But that is neither here nor there.

Referring to her 1995 book After the Light, Sharp urges that the story has not changed "an iota since day one" even though her memory of the details "has certainly been affected." But my original citation was of her first published report of the case seven years after the fact, in 1984, not her reconstruction of it yet another 11 years later. The details reported closest to the event itself are less susceptible to the sorts of memory distortions that Sharp herself acknowledges have been a factor in her recounting of that now 30-year-old case.

Since I am not in any position to defend the details of Hayden Ebbern and Sean Mulligan's field investigation, I will only note that, had the investigators revealed their intention to write a skeptical critique of the case at the outset, it is doubtful that Sharp would have allowed them to perform a proper field investigation in which her previous claims about the case would be directly put to the test.

In response to the fact that the investigators were able to discern their own "test shoe" so easily in 1994, on the window ledge Sharp identified as the location of Maria's shoe, Sharp claims that she simply guessed the exact location of Maria's shoe because Ebbern and Mulligan were uncomfortably persistent in pushing her for an exact location. This strikes me as an incredibly convenient reply to the discovery of a detail that she admits previously reporting but which a follow-up investigation found to be erroneous. Just how bullying could "a couple of kids from a small Canadian college" that she wanted to help out really be?

Sharp then turns to another reported detail that turned out to be erroneous: how difficult it would be to see a tennis shoe on a window ledge from inside the overlooking hospital room. Her statement that the relevant window ledges were not visible from inside the overlooking rooms unless she pressed her face hard against the window was purportedly just a simplification, but it was undoubtedly a rather convenient one, since it happens to bolster the case's impressiveness. She mentions, for instance, that in some rooms "things were stacked 
up against the lower part of the windows" making it difficult to see the window ledges; but was that the "configuration" of the room in which Maria's shoe was discovered? If not, there was certainly some misleading innuendo in describing how difficult it was to see the window ledges, since the room where the shoe was actually discovered is the only room that matters as far as the visibility of the ledge from inside the room is concerned.

Next, Sharp reveals that she could have introduced the investigators to hospital staff who had met Maria and listened to her story if they had asked for as much. But even so, their secondhand testimony of events that happened nearly two decades earlier would never be as good as early testimony directly from Maria herself. The earliest testimony we have to go on for discerning the facts of this case is Sharp's alone - her already cited 1984 paper - and subsequent investigation by Ebbern and Mulligan uncovered serious problems with the reliability of that account (Ebbern, Mulligan, and Beyerstein, 1996).

Although Maria was hospitalized long enough prior to her NDE to become familiar with her monitoring equipment, Sharp retorts that "There is absolutely no way" Maria could have known by normal means that electrocardiogram (EKG) printouts flowed onto the floor and were kicked under the beds because "No one ever educates a cardiac patient to that level of detail." But that sort of fact need not ever be taught, discussed, or shown in media portrayals of cardiac arrest in order for Maria to have learned about it by normal means. Maria was monitored by such equipment for three days before she had her NDE. Are we to really believe that in all that time there is no way that she could have observed EKG printouts from machines in close proximity to her bed?

Sharp explains the ease at which the investigators saw their own "test shoe" in 1994 in terms of their unproblematic vantage point compared to hers back in 1977: "When I looked for the shoe from the ground, I was following a sidewalk that hugged the building, completely unable to see something visible on the ledge a few stories above me." She complains that, instead of doing a room-by-room search from inside the hospital for the shoe on the ledge, she wishes she would have thought of looking for the shoe from further away when she was outside of the building. But whether Sharp herself could see the shoe after a superficial search of the building's perimeter is immaterial to whether Maria could have gained knowledge of its 
location by normal means. I emphasized the ease with which the investigators saw their "test shoe" from outside in 1994, at the spot where Maria's shoe was reportedly located in 1977, because others within earshot of Maria's hospital bed could have easily noticed the shoe from outside before entering the hospital back in 1977. This focus was clear when I pointed out that the investigators' construction area was a "high-traffic parking lot and recreation area back in 1977" and that the unpublicized "test shoe" from 1994 was so conspicuous from outside that by the time of the investigators' next visit, the "test shoe" had already been removed, before explicitly noting that Maria could have overheard a conversation about the shoe she reported. Though Sharp does add that this scenario is unlikely because Maria purportedly "spoke very little English," it is impossible to verify this detail now since Maria is presumably long dead and no one even knows who she really was.

Sharp notes that in the seven years between Maria's NDE and Sharp's first published report of it, she discussed the case in casual conversation and even on a local television show. But her occasional conversations are not part of any verifiable record we can now check, and her brief comments in a live television interview are unlikely to have revealed very much about the case. Full details awaited the publication of After the Light (Sharp, 1995) nearly 20 years later, and who knows how many factual errors could have crept into Sharp's account after all of that time?

Finally, Sharp interpreted the point that she may have shaped her account of Maria's NDE over the years as an accusation of lying. But potential embellishment does not necessarily imply deception, as people tend unintentionally to remember details that support a narrative while forgetting those that contradict it. Though embellishment is not something that a person is typically conscious of, it is an established factor in how memories are reconstructed. Some details are remembered accurately, some are forgotten, and some are subconsciously "invented" to fill in the gaps and produce a coherent narrative structure. It is near-death researchers' responsibility to rule out such conventional explanations before demanding that the scientific community overhaul its current understanding of human nature.

Charles Tart finds fault with my characterization of the Reynolds case as "infamous." What I should have said is that the case was immediately hailed by near-death researchers eager to highlight 
purportedly veridical paranormal perceptions during out-of-body NDEs.

Nevertheless, characterizing my observation of the sensationalism and misrepresentations surrounding the case as an "a priori dismissal" is simply incorrect. I cited near-death researchers hailing the "inexplicability" of the case from the outset, and directly quoted misrepresentations in the parapsychological and medical literature. Van Lommel and colleagues, for instance, referred to verifiable perceptions during a period of flat electroencephalogram (EEG) that never happened (van Lommel, van Wees, Meyers, and Elfferich, 2001).

My statement that Reynolds's NDE implied the operation of normal perception within a nonthreatening physiological condition struck Tart as "an odd way to characterize being effectively dead with only the hope that the equipment and surgeons will pull you back." But indisputably, Reynolds's out-of-body NDE began hours before she was, by any criteria, effectively dead. And since I explicitly referred to her veridical perceptions in that sentence, I was clearly referring to the out-of-body component of the experience. No one disputes that during her period of veridical perception, when her experience began, there was nothing more than general anesthesia for Reynolds to be "pulled back" from. That Reynolds would be brought to the brink of death at some point during the procedure would indeed "make the surgery a pretty threatening condition from a psychological perspective," which is precisely why I suggested that fear triggered the experience.

Tart then complains that my statement that Reynolds's NDE did not occur when any of her EEG recordings were flat "is biased and incorrect"; but it is neither. While conceding that her NDE began well before standstill, he argues that her description of the remainder of her experience "clearly" implied that her NDE continued all the way through "and beyond the reinfusion of warmed blood." But because the remainder of her experience lacked any veridical elements, it is impossible for us - or her - to timestamp any elements of her NDE subsequent to her OBE. Her entire NDE could have occurred well before standstill; two hours certainly seems ample time for such an experience to run its course. Indeed, Tart himself says that this is the most natural way to read the experience when he concedes that "Sabom's presentation of Reynolds's NDE did not seem to fill all that time."

To my statement that Reynolds's cerebral cortical inactivity did not exceed about a half hour, Tart replies: "Thirty minutes of complete 
cardiac arrest and absent brainwaves are certainly sufficient to raise questions about her ability to think clearly and perceive accurately during that period." But that any part of her NDE occurred during this period is precisely the issue in contention. There is no evidence that any part of Reynolds's NDE occurred during a period of "complete cardiac arrest and absent brainwaves," and consciousness in the absence of brain activity is an extraordinary claim requiring extraordinary evidence before we are warranted in accepting it. By contrast, consciousness during anesthesia awareness has a comparably much higher initial probability, and we already know that Reynolds's NDE began when her brain was functioning normally.

Tart suggests that Sabom's account was merely ambiguous rather than intentionally misleading; but the important point is that he was misleading, intentionally or not. Why else would Braude characterize the case as a "detailed veridical near-death OBE" during a period of "flat EEG and absence of auditory evoked potentials from her brainstem" (Braude, 2003, p. 274), while later concluding that "the case for survival receives very little independent support from OBEs, NDEs, and apparitions" (2003, pp. 280-281). Although Tart claims that "Sabom made it quite obvious that her NDE began well before cardiac standstill," he does not cite a single supporting sentence from Light \& Death (Sabom, 1998). Moreover, Sabom repeatedly associated Reynolds's NDE with the time when she was clinically dead, despite knowing that whatever triggered her NDE occurred well before, and thus had nothing to do with, the induction of hypothermic cardiac arrest.

Surprisingly, Tart argues that because Reynolds also attributed her NDE to the period "up to and beyond warmed blood infusion," her testimony "makes Sabom's inference quite reasonable." But except in cases when bodily sensations, such as chest compressions, or veridical perceptions, such as heard conversations, are incorporated into NDEs themselves, NDErs have no more means to correlate parts of their experiences with specific physiological events than we do. So Tart's accusation is false that assuming that Reynolds's NDE ended before standstill "ignores experiential evidence"; for the only potentially relevant experiential evidence is absent subsequent to the out-of-body component of her NDE.

Though Tart concedes that "Sabom's presentation of Reynolds's NDE did not seem to fill" the hours preceding cooled blood infusion, he adds that Reynolds's description implies that many other things that Sabom did not ask her about occurred. Such speculation is shaky 
grounds on which to resist so natural a conclusion. Moreover, Light \& Death (Sabom, 1998) contains the nearest first-person testimony to the experience itself, and consequently is inherently more reliable than any subsequent testimony from Reynolds.

Next Tart accuses me of "a major distortion of the facts" in describing Sabom's "small molded speakers" as "small earphones," even though I quote Sabom's description immediately after offering my own, as I evidently "counted on everyone knowing" that "sound from the room can leak in around" earphones to bolster my own case. $\mathrm{He}$ asserts that small molded speakers "shut out sounds much more effectively" than standard earphones. But "small molded speakers" do not completely eliminate external sounds; they only reduce their intensity. A minor change in terminology hardly warrants the conclusion that it was impossible for Reynolds to pick up a conversation through normal hearing.

Tart's most poignant observation concerns "the 100-decibel level of these clicks [in the molded speakers], which is the level of sound of a full symphony orchestra playing really loud, masking room noise quite effectively." That level of volume would certainly drown out any interoperative conversations.

However, was the machine designed to measure auditory evoked potentials (AEPs) actually turned on and generating clicks at the time that Reynolds overheard an operating room conversation? It is plausible that Reynolds's speakers would not be operational at the time of her veridical perceptions - about 8:45 AM - given that her brainstem activity would not be expected to falter two hours in advance of hypothermia. But even if such equipment was fully functional at such an early stage, we would need to know the duration of the silent pauses between 100-decibel clicks to conclude that it was impossible for Reynolds to recall sufficiently coherent fragments of an overheard conversation.

That I discounted the paranormal veridicality of Reynolds's NDE report "because she did not provide positive visual descriptions of everything that happened" is not faithful to my original point: that Reynolds's description of her "perceived" instrument noted features that the instrument used did not have - exactly what one would expect if her imagery was reconstructed from scraps of conversation rather than obtained through eyeless vision.

Although Reynolds's knowledge of her shaved head hardly required paranormal abilities, Tart snapped back that any normal explanation 
requires one to assume that she lied about her experience. But that she learned about how her head was shaved subsequent to her NDE is only one possible explanation. Another is that she learned that her head would be shaved in a particular way prior to her experience, consciously forgot about this, and that that information resurfaced during her OBE. Second, she could have unintentionally incorporated a detail that she had actually learned subsequent to the experience itself. The brain often fabricates details in order to make different memories consistent with each other within a coherent narrative. Surely if Reynolds had become aware that her head had been shaved in a certain way subsequent to her experience - and we know that she must have - her brain would bias her to "remember" the same detail whenever she recalled her NDE.

Tart dismisses memory distortions on the shakiest of grounds: that NDErs typically report vivid memories, and that there is no statistical evidence that, in general, NDErs significantly alter their accounts over time. But even if NDErs do not generally embellish, that is no indication that embellishment was not a factor in this case specifically. Second, it is arguable that the (varied) statistical measures of embellishment within accounts have really been fine enough to discern subtle changes within the accounts considered. Had the Reynolds case been included among any of these studies' samples, would a change in Reynolds's description of how her hair was shaved have been detected?

Tart characterizes the possibility of anesthesia awareness as an accusation of incompetence on the part of Reynolds's anesthesiologists. Yet most cases of anesthesia awareness do not result from human error, but from the fact that different people respond to anesthetics differently. He adds that while anesthesia awareness is theoretically possible, "it is the wildest speculation postulating a highly unlikely event." Is he suggesting that the ad hoc postulation of a form of eyeless vision completely unknown to science to explain ostensibly veridical perceptions during OBEs and similar experiences but nothing else is somehow more likely than an undoubtedly real phenomenon like anesthesia awareness?

Tart rightly notes that just because some NDEs are triggered by fear does not imply that all of them are. But since no physiological threat precipitated Reynolds's $N D E$, fear is the most likely cause. For if not fear, then what? anesthetics? Because no immediate medical crisis existed at any time even close to when her experience began, there are not many potential candidates for its cause. 
Sabom writes in his commentary that the important point is not when Reynolds's NDE began, but when it ended. But if her NDE began so far from any immediate medical threat, the fact that she would eventually come close to death a few hours later is rather incidental to her experience. Evidently, her NDE would have occurred even if, after she was anesthetized, hypothermic cardiac arrest had been postponed until another day. Furthermore, when her experience began is surely relevant to when it plausibly ended. It is plausible (though not demonstrable) that her NDE ran its entire course before hypothermia was induced.

To support his contention that Reynolds's NDE proceeded beyond hypothermic cardiac arrest up until she awoke from general anesthesia, Sabom adds that Reynolds herself "described her NDE as an uninterrupted, continuous experience." But just because Reynolds's experience felt continuous does not entail that it was uninterrupted from beginning to end. We cannot rule out that her experience began prior to hypothermia, ended when she slipped into unconsciousness as hypothermia deepened, and resumed with the reinfusion of warm blood, after her brain activity had been restored. Aside from the overheard conversation and sequence of events in her NDE, there is no way definitively to correlate specific parts of her subjective experience with specific physiological events. Any period without conscious awareness would not be felt by Reynolds, and so any interruption would not be evident to her. So the fact that Sabom constructed his account of Reynolds's NDE as a continuous experience "based entirely on her testimony" does nothing to validate the reliability of that construction. Every subjective element of Reynolds's experience that Sabom correlates "with events in the operating room" beyond those early auditory perceptions is pure speculation.

Sabom quotes Arthur Hastings to the effect that, if we assume that the OBE component of an NDE involves the actual perception of the physical world, it is both natural and reasonable to anticipate that the continuation of the NDE beyond that component also involves the perception of "some kind of independent reality" (Hastings, 2002, p. 94). I agree; indeed, faced with compelling evidence for veridical paranormal perception during out-of-body NDEs, I think that the burden of proof would fall on proponents of a rather ad hoc, unfalsifiable, and blanket super-ESP hypothesis to demonstrate otherwise. But we cannot just assume that out-of-body imagery present during NDEs is "valid" rather than hallucinatory, even when 
NDE reports incorporate accurate information that could have been obtained through normal means such as hearing.

Sabom asserts that my statement that Reynolds's NDE did not take place "during any period of flat EEG" was invented out of thin air. But we know that her experience began well before any such period and "did not seem to fill all that time" up to either cortical or brainstem flatline. The burden of proof falls on Sabom to show that any part of her NDE must have taken place during brainstem flatline, for we have never corroborated any human experience that was not mediated by brain activity. Sabom adds that my reconstruction assumes a discontinuity that "runs counter to Reynolds's testimony." But it does not assume either a physiological or subjective discontinuity, as the entire experience could have taken place before hypothermia. Though I do not assume a physiological discontinuity, one is certainly compatible with the facts. Moreover, even if I had assumed physiological discontinuity, that would not have implied any subjective interruption, since unconscious periods are not perceived.

Sabom assures us that the "mounds of tape and gauze" securing Reynolds's molded speakers would have made her ability to overhear an operating room conversation by normal means during her procedure "extremely unlikely." But the only way to know for sure would be to place similarly fitted subjects under conditions matching, as closely as possible, those that Reynolds encountered. Such an experiment could be performed under the pretense of a perceptual test, while operating-room-like conversations were played in close proximity to subjects who would later be quizzed on the contents of those conversations.

Sabom concludes that because he explicitly stated that, by definition, Reynolds was never truly dead, this absolves him of any responsibility for the misrepresentations made by other researchers. But Sabom's qualification only concerned an issue of semantics -how "death" is defined - not whether Reynolds was having conscious experiences during brainstem flatline. That is the real issue here, and Sabom's reconstruction clearly encouraged the perception that Reynolds was conscious during a period of "complete electrocerebral silence" (Sabom 1998, p. 43), a period that Tart's commentary characterized as "being effectively dead." So when Sabom wrote that "NDEs are not accounts of life after death" (1998, p. 51$)$, he was arbitrarily picking out one meaning of the term "death," not all possible meanings or even the most relevant one. Finally, that Sabom 
devoted a few sentences in Light \& Death (Sabom, 1998) to alternative explanations for Reynolds's ostensibly paranormal perceptions, and concluded on a note of uncertainty, is no indication of the general orientation of the relevant chapters. Disclaimer aside, Sabom undoubtedly steered his discussion in a direction that favored a paranormal interpretation of the facts of the case.

\section{References}

Alvarado, C. S. (2000). Out-of-body experiences. In E. Cardeña, S. J. Lynn, and S. Krippner (eds.), The varieties of anomalous experience: Examining the scientific evidence (pp. 183-218). Washington, DC: American Psychological Association.

Beloff, J. (1992). Is there anything beyond death? A parapsychologist's summation. In $P$. Edwards (ed.), Immortality (pp. 259-268). New York, NY: Macmillan.

Blackmore, S. (1993). Dying to live: Near-death experiences. Buffalo, NY: Prometheus.

Braude, S. (2003). Immortal remains: The evidence for life after death. Lanham, MD: Rowman and Littlefield.

Broad, C. D. (1925). The mind and its place in nature. London, England: Routledge and Kegan Paul.

Broughton, R. S. (1991). Parapsychology: The controversial science. New York, NY: Ballantine.

Curlin, F. A., Lantos, J. D., Roach, C. J., Sellergren, S. A., and Chin, M. H. (2005). Religious characteristics of U.S. physicians: A national survey. Journal of General Internal Medicine, 20,629-634.

Dillard, A. (2000). For the time being. New York, NY: Vintage.

Ebbern, H., Mulligan, S., and Beyerstein, B. (1996, July/August). Maria's near-death experience: Waiting for the other shoe to drop. Skeptical Inquirer, 20(4), 27-33.

Geach, P. (1992). Immortality. In P. Edwards (ed.), Immortality (pp. 225-234). New York, NY: Macmillan.

Greeley, A. M., and Hout, M. (1999). Americans' increasing belief in life after death: Religious competition and acculturation. American Sociological Review, 64, 813-835.

Greyson, B. (2000). Near-death experiences. In E. Cardeña, S. J. Lynn, and S. Krippner (eds.), The varieties of anomalous experience: Examining the scientific evidence (pp. 315-352). Washington, DC: American Psychological Association.

Greyson, B. (2007). Consistency of near-death experience accounts over two decades: Are reports embellished over time? Resuscitation, 73, 407-411.

Hastings, A. (2002). The resistance to belief. Journal of Near-Death Studies, 21, 77-98.

Haub, C. (1995). How many people have ever lived on earth? Population Today, 23, 4-5.

Humphrey, N. (1996). Leaps of faith: Science, miracles, and the search for supernatural consolation. New York, NY: Basic Books/HarperCollins.

Irwin, $H$. (2002). Is scientific investigation of postmortem survival an anachronism? The demise of the survival hypothesis. Australian Journal of Parapsychology, 2, 19-27.

Larson, E. J., and Witham, L. (1996). Scientists are still keeping the faith. Nature, 386, $435-436$.

McConnell, R. A., and Clark, T. K. (1980). Training, belief, and mental conflict within the Parapsychological Association. Journal of Parapsychology, 44, 245-268.

Moody, R. A. (1975). Life after life: The investigation of a phenomenon-survival of bodily death. Covington, GA: Mockingbird Books.

Moody, R. A. (1977). Reflections on life after life: More important discoveries in the ongoing investigation of survival of life after bodily death. New York, NY: Bantam. 
Moody, R. A., and Perry, P. (1990). Life before life: Regression into past lives. New York, NY: Macmillan.

Moody, R. A., and Perry, P. (1993). Reunions: Visionary encounters with departed loved ones. New York, NY: Villard.

Potts, M. (2002). The evidential value of near-death experiences for belief in life after death. Journal of Near-Death Studies, 20, 233-258.

Radin, D. (1997). The conscious universe: The scientific truth of psychic phenomena. San Francisco, CA: HarperSanFrancisco.

Ring, K. (2000). Religious wars in the NDE movement: Some personal reflections on Michael Sabom's Light \& Death. Journal of Near-Death Studies, 18, 215-244.

Ring, K., and Valarino, E. E. (2000). Lessons from the light: What we can learn from the near-death experience. New York, NY: Plenum/Insight.

Sabom, M. (1998). Light \& death: One doctor's fascinating account of near-death experiences. Grand Rapids, MI: Zondervan.

Sartori, P. (2004). A prospective study of NDEs in an intensive therapy unit. Christian Parapsychologist, 16, 34-40.

Sharp, K. C. (1995). After the light: What I discovered on the other side of life that can change your world. New York, NY: William Morrow.

Thatcher, R. (1996). The living dead. New Scientist, 2011, 69.

van Lommel, P., van Wees, R., Meyers, V., and Elfferich, I. (2001). Near-death experiences in survivors of cardiac arrest: A prospective study in the Netherlands. Lancet, 358, 2039-2045.

Woerlee, G. M. (2005). An anaesthesiologist examines the Pam Reynolds story. Part two: The experience. The Skeptic (UK), 18, 16-20. 